13. Ефремова Н. И. Теория и методика музыкально-ритмического воспитания: модель курса (презентация дисциплины) // Вестник Челябинской государственной академии культуры и искусств. — 2012. — № 3 (31). - C. 97-101.

14. Зуева С. П. Развитие музыкального творчества детей дошкольного возраста через использование системы элементарного музицирования // Молодой ученый. — 2012. — № 10(45). — С. 331-333.

15. Кирнарская Д.К. Психология специальных способностей. Музыкальные способности. - М.: Таланты-XXI век, 2004. - $496 \mathrm{c.}$

16. Корлякова С. Г. Островерхов А. Г. Музыкально-ритмическая способность в структуре музыкальных способностей: ретроспективный анализ // Мир науки, культуры, образования. — 2016. — № 5(60). — С. 272273.

17. Корлякова С. Г. Островерхов А. Г. Музыкально-ритмическая способность как компонент музыкальных способностей// Мир науки, культуры, образования. - 2013. - № 5(42). - С. 79-81.

18. Леонтьева О. Т. Книга о Карле Орфе. - М.: Композитор, 2010. - 512 с.

19. Лялин К. О. Особенности развития чувства ритма у младших подростков// Инновации и традиции в сфере культуры, искусства и образования: материалы научно-практической конференции в рамках Дней науки МГПУ. - М.: Перо, 2018. — С. 187-194.

20. Немцева Д. Г. Применение здоровьесберегающей техники «боди перкашн» на уроках сольфеджио в детской музыкальной школе // Современные тенденции общего и дополнительного музыкального и художественного образования: сб. науч. тр. / отв. ред. Л. В. Матвеева. - Екатеринбург: УрГУ, 2020. - С. 96-100.

21. Овчинникова Т.С. Логопедические распевки. - СПб: КАРО, 2019. - 64 с.: ил. (Популярная логопедия)

22. Приказ Министерства культуры РФ от 12 марта 2012 г. № 162 «Об утверждении федеральных государственных требований к минимуму содержания, структуре и условиям реализации дополнительной предпрофессиональной общеобразовательной программы в области музыкального искусства „Народные инструменты“ и сроку обучения по этой программе»// Гарант. Ру [электронный ресурс]. — URL: https://www.garant.ru/products/ipo/prime/doc/70053524/

23. Приказ Министерства просвещения РФ от 31 мая 2021 г. № 287 “Об утверждении федерального государственного образовательного стандарта основного общего образования”// Гарант.Ру [электронный pecypc]. - URL: https://www.garant.ru/products/ipo/prime/doc/401333920/

24. Римский-Корсаков Н. А. Музыкальные статьи и заметки. О музыкальном образовании. - Спб.: тип. М. Стасюлевича, 1911. - 223 с.

25. Старчеус М. С. Слух музыканта. - М.: Моск. гос. консерватория им. П. И. Чайковского, 2003. - 640 с.

26. Тарасова К. В. Онтогенез музыкальных способностей. — М.: Педагогика, 1988. — 173,[2] с. : ил.

27. Теплов Б. М. Психология музыкальных способностей/Избранные труды: В 2 т. - М., 1985. - Т. 1. - 328 с.

28. Техническое описание компетенции R57 «Преподавание музыки в школе» // Worldskills.ru [электронный pecypc]. — URL: worldskills.ru/final2020/wp-content/uploads/2020/06/\%D0\%A2\%D0\%9E-287.docx

29. Тухватуллина Э. А. Новые тенденции в детском хоровом исполнительстве (применение ритмического жанра body percussion) // Современное образование: актуальные вопросы и инновации. — 2019. — № 3. — С. 4147.

30. Цагарелли Ю. А. Психология музыкально-исполнительской деятельности: учеб. пособие. - СПб.: Композитор, 2008. - 368 с.

31. Цыпин Г. М. Психология музыкальной деятельности: проблемы, суждения, мнения: Пособие для учащихся муз. отд-ний педвузов и консерваторий/Г. М. Цыпин. - М.: Фирма "Интерпракс", 1994. - 373 с.

32. Шелепова Д. А. Body percussion как средство развития чувства ритма у детей младшего школьного возраста // Культурные инициативы: материалы 52 Всероссийской научной конференции молодых исследователей / сост. и науч. ред. Ю. В. Гушул, отв. за выпуск С. Б. Синецкий, И. М. Баштанар. — Челябинск: ЧГИК, 2020. - C. 337-339.

\title{
Куцобина Н.В., Пугачёва Л.М. \\ К вопросу об инклюзивном образовании в изучении иностранного языка в рамках технического вуза
}

Брянский Государственный Технический Университет

(Россия, Брянск)

doi: 10.18411/trnio-10-2021-09

\section{Аннотация}

В данной статье рассматриваются вопросы формирования интеллектуальных компетенций студентов с ограниченными возможностями в рамках технического вуза.

Ключевые слова: студенты с расстройствами аутистического спектра, инклюзивное обучение, аутизм, инклюзия. 


\section{Abstract}

This article deals with intellectual competences of students with disabilities at technical higher schools.

Keywords: students with autism spectrum disorder, inclusive environment, autism, inclusion.

В последние годы в нашей стране наблюдается катастрофическое увеличение числа молодых людей с ограниченными возможностями здоровья, что является определяющим фактором при переходе на инклюзивную, интегрированную форму обучения и воспитания в вузе. Обучение происходит в условиях социальной инклюзии: занятия проводятся в тех же аудиториях, где обучаются обычные студенты, отдыхают на перерывах, находятся в среде сверстников.

Нам пришлось столкнуться с обучением студентов с расстройством аутистического спектра (РАC) с разной степенью выраженности интеллектуальных нарушений.

Термин АУТИЗМ происходит от латинского слова autos, что означает «погружение в себя, в свой внутренний мир». Аутизм - нарушение развития, связанное с изменениями работы мозга. Аутизмом страдают лица независимо от половой и расовой принадлежности или социально-экономического положения. В первую очередь, для аутизма характерны уникальные особенности в плане социального взаимодействия, сложности в повседневном общении и нестандартный способ обработки информации.

В российских исследованиях аутизма 1990-х было отмечено, что швейцарский исследователь-психиатр Эйген Блейлер, автор этого термина, выдвинул два аспекта структуры аутизма: 1) внешний, поведенческий, с нарушением поведения в обществе и уходом от действительности 2) внутренний, ведущий, содержательный — аутистическое мышление.

Немецкий психиатр Карл Ясперс описывал аутизм как «самозаточение в собственном изолированном мире». Он указывал, что одна из сторон аутизма - концентрация на собственных фантазиях, независимо от реальности, и отсутствие способности различать реальность как таковую, и учитывать её должным образом.

С. М. Корсунским аутизм описан как «особый аффективно построенный мир, не зависящий от логических законов, являющийся продуктом ослабления логического мышления и мыслящий желания осуществлёнными».

Второго апреля ежегодно отмечается Всемирный день распространения информации о проблеме аутизма (World Autism Awareness Day), который был утвержден резолюцией Генеральной Ассамблеи ООН от 18 декабря 2007 г., в связи с особой обеспокоенностью ростом заболеваемости детей аутизмом. [1]

Спектр РАC многогранен и неустойчив: гиперактивность, заторможенность, агрессивность, боязнь, замкнутость, неумение воспринимать обращенную к ним речь. В вузе зачастую обучаются молодые люди с аутизмом с сохраненным интеллектом с так называемыми «высокофункциональными» когнитивными способностями. [2]

Для высокофукционального аутизма, в первую очередь, характерны трудности с пониманием разговорного стиля языка, затруднения, связанные с изменением устоявшегося распорядка, строгого соблюдения плана занятия, нетолерантное отношение к другим обучающимся в группе.

Высокофункциональный аутизм (англ. high-functioning autism, сокращенно HFA) общее нарушение психического развития, одна из форм аутизма. Термин относится к людям с аутизмом, чей коэффициент интеллекта (IQ) больше 70, поэтому их когнитивные способности оцениваются как «высокофункциональные». Черты высокофункционального аутизма - сложности в социальных навыках и некоторая неуклюжесть, а также задержки в речевом развитии, характерные и для некоторых других форм аутизма. [3]

Поэтому учебное занятие целесообразно строить на основе использования различных форм обучения, в том числе с включением наглядных материалов (в нашем случае 
визуальных карточек). При этом объяснение нового материала должно быть предельно простым, повторяющимся неоднократно, в одних и тех же выражениях и с той же последовательностью. Речевые конструкции должны быть несложными, изображения на карточках - в спокойных тонах с исключением ярких цветов, которые могут вызвать негативную реакцию обучающегося. [4]

Следует предъявлять материал голосом разной громкости, но обязательно без повышения тона, спокойно, зачастую переходя на шепот. В завершении задания преподаватель обращает внимание студента на его успехи, даже если они минимальны.

Одним из эффективных методов обучения иностранному языку студентов с ограниченными возможностями является, по нашему мнению, метод с применением визуальных опор. При изучении темы «Образование десятков в английском языке» мы начали рассмотрение данной темы с числительных 50, 70 и 90, так как во- первых, данные числительные принадлежат к одному ряду- нечётных, а во -вторых их образование основано на ранее изученных числительных $5,7,9$. Количество изучаемых нами числительных было ограниченно только этими тремя цифрами, так как при работе со студентами с ограниченными возможностями следует учитывать количество информации, которую они могут воспринимать за один раз. Изучение было основано на применении в процессе обучения наглядного материала - карточек. Используя их, мы сначала объяснили принцип образования десятков, а именно:

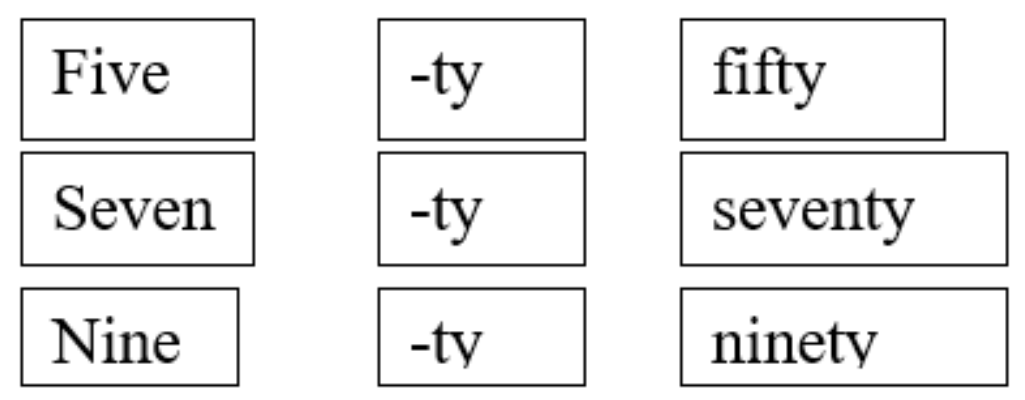

Было уделено внимание чередованию согласных в числительном «fifty». Затем студентам предложили за преподавателем самим ещё раз повторить образование десятков с опорой на карточки.

Следующим упражнением было прочитать за преподавателем ряд числительных, состоящих из десятков и единиц. Следует обратить внимание студентов на написание в английском языке данных числительных, а именно, в составном количественном числительном десятки от единиц отделяются тире:

5 five [faiv]

50 fifty [fifti]

55 fifty- five [fifti faiv]

57 fifty-seven [fifti sevn]

59 fifty-nine [fifti nain]

7 seven [sevn]

70 seventy [sevnti]

75 seventy- five [sevnti faiv]

77 seventy- seven [sevnti sevn]

79 seventy- nine [sevnti nain]

9 nine [nain]

90 ninety [nainti]

95 ninety- five [nainti faiv]

97 ninety- seven [nainti sevn]

99 ninety- nine [nainti nain] 
Для закрепления материала студентам было предложено при помощи визуальных опор сложить числительные в том же порядке и произнести их по-английски.

По опорному образцу обучающиеся составили числительные, называя их:

a) денежные суммы в пенсах

Дано: 50p

Требуется: fifty $\mathrm{p}$ [fifti pi:]

50p, 55p, 57p, 59p, 70p, 75p, 77p, 79p, 90p, 95p, 97p, 99p.

б) количество

50 seats, 55 types, 57 sets, 59 files, 70 seats, 75 types, 77 sets, 79 files, 90 seats, 95 types, 97 sets, 99 files.

в) номера и буквенные обозначения

seat 50 , type $55-\mathrm{A}$, set 57 , file 59 , seat $70-\mathrm{D}$, type 75 , set $77-\mathrm{F}$, file 79 , seat $90-\mathrm{B}$, type 95 , set 97, file 99.

Для закрепления грамматического материала студенты выполнили упражнение на подражание образцу:

lesson $50-50$ lessons list $77-77$ lists

type $55-55$ types team $79-79$ teams

set $57-57$ sets $\quad$ step $90-90$ steps

file 70 - 70 files seat $99-99$ seats

Для развития навыков перевода обучающимся было предложено прочитать и перевести следующие предложения:

1. $\quad$ Please send me 55 sets. - Please send me set 55.

2. $\quad$ Please lend me 57 files. - Let me see file 57.

3. $\quad$ Please type 70 lists. - Please type list 70.

4. $\quad$ Please find 79 tests. - Please find test 79.

5. $\quad$ Please see 95 slides. - Please see slide 95.

Для развития навыков диалогической речи студентам предложили разыграть диалоги, заменяя выделенные слова словами, данными в скобках.

1

A. Let me see slide 55, please.

B. 55 slides?

A. Slide 55.

B. Yes, please.

(file 57, set 70, list 97)
2

A. Miss Flynn!

B. Yes?

A. Lend me 50p, please.

B. $50 p$ ?

A. Oh, yes. (55p, 79p, 90p)

Итак, для формирования грамматической компетенции основным принципом в работе со студентами является принцип повторяемости изучаемого материала.

Изучив педагогический опыт работы с обучающимися с РАС, в частности, собранный и представленный МБУ ДО «ЦВР Промышленного района» г. Ставрополя, можно подтвердить эффективность общих психолого-педагогических рекомендаций по взаимодействию с молодыми людьми с ограниченными возможностями.

Студенты, имеющие нарушения аутического спектра, лучше воспринимают информацию визуально, чем на слух не потому, что они не слышат, а потому, что иначе воспринимают информацию. Фразы типа «Я тебе сто раз это сказала» не работают. Надо объясняться проще, сопроводив просьбу картинкой или знакомыми словами, четко поставить цель или дать поручение. Медленный, спокойный темп речи уравновешивает реакции обучающегося. Иносказания в речи преподавателя не допустимы, так как воспринимаются в буквальном смысле. [5]

Коммуникация со студентом, у которого наблюдаются расстройства аутистического спектра, не должна происходить в спешке. Не стоит ждать моментального ответа. Время обработки информации у всех разное. У одних - это минута, у других - десять и больше. И если торопить студента с ответом, можно только усугубить ситуацию. 
За студентом с РАС следует сразу закрепить место, где он должен сидеть, четко объяснить, где и что можно делать. Если это вызывает протест или неприятие, дать время успокоиться (у каждого человека есть какие-то ритуалы, которые успокаивают его), потом персонально показать и разъяснить еще раз.

Особое внимание следует уделить так называемому положительному подкреплению. Не стоит концентрироваться на порицаниях в случае, когда студент ведет себя «странно». Если такое поведение не выходит за рамки допустимого, лучше проигнорировать такую ситуацию. Надо дождаться момента, когда обучающийся сделает то, что от него хочет преподаватель, и незамедлительно поощрить его. Положительное подкрепление работает гораздо эффективнее наказания.

Таким образом, поработав со студентами с ограниченными возможностями, в частности, с расстройствами аутистического спектра, при обучении иностранному языку, мы считаем, что инклюзия данной категории молодых людей в обычных студенческих группах возможна и способствует более эффективному развитию личности обучающихся. Этому же способствует и позиция педагогов воспринимать воспитанников с РАС как активных студентов группы и находить индивидуальный подход к ним, а также умение применять множество специализированных средств обучения.

К сожалению, нельзя не отметить и отрицательный аспект такой интеграции, а именно повышенную напряженность и шум в учебной аудитории, нарушение типовых процедур урока, увеличение по времени затрат преподавателя на планирование и подготовку к занятиям.

$$
* * *
$$

1. Хачанян, 3.Т. Развитие личности обучающихся, имеющих нарушения аутического спектра в условиях допобразования // Дополнительное образование и воспитание.- 2020.- №11.- С.16-18

2. Волкова, О.О. Опыт и перспективы профессионального обучения молодых людей с аутизмом // Профессиональное образование. Столица. - 2018.- №5.- С.28-32

3. Интернет-ресурс: https://ru.wikipedia.org/wiki/Аутизм_(симптом) (Дата обращения: 19.02.21)

4. Аттитюды педагогов в отношении инклюзивного образования детей с РАС: обзор отечественных и зарубежных исследований // Образование и наука.- 2019.- Т.21, №10.- С.189-210

5. Демичева, О.Г. Неспециальные проблемы инклюзивного образования // Народное образование. - 2012. C.242-245.

\section{Маренина Т.A. \\ Проблемы дошкольного образования}

МАДОУ детский сад № 146

(Россия, Тюмень)

doi: 10.18411/trnio-10-2021-10

Аннотация

В статье исследуются глобальные проблемы детских садов. В результате исследования сформулированы области, на которые необходимо обратить внимание и в дальнейшем найти оптимальные пути решения.

Ключевые слова: дошкольное образование, образовательная среда, педагогические кадры, развитие дошкольных организаций, стандарт.

\section{Abstract}

The article examines the global problems of kindergartens. As a result of the research, the areas that need to be paid attention to and further find optimal solutions are formulated.

Keywords: preschool education, educational environment, teaching staff, development of preschool organizations, standard. 